\title{
APONTAMENTOS DE ÁLVARO VIEIRA PINTO À REFORMA UNIVERSITÁRIA NO BRASIL NA DÉCADA DE 1960
}

\author{
Cristiane Silva Mélo ${ }^{1}$ \\ Maria Cristina Gomes Machado² \\ Universidade Estadual de Maringá (UEM/CNPq)
}

\section{RESUMO}

Este artigo resulta de um estudo desenvolvido acerca dos debates antecedentes à Reforma do Ensino Superior, Lei ${ }^{\circ} 5.540$ de 1968, em que foi possível conhecer as contribuições do educador Álvaro Vieira Pinto (1909-1987) nas discussões sobre a situação e o papel da universidade no Brasil, bem como na definição de propostas para alterações e desenvolvimento desse sistema de ensino na década de 1960. O texto apresenta as proposições de Vieira Pinto sobre a reforma e a organização do ensino superior brasileiro, baseando-se, em especial, na análise de sua obra A Questão da Universidade (1986) escrita em 1961, que aborda aspectos do modelo de universidade vigente e do modelo almejado no país naquele momento. Na perspectiva do autor, o problema da universidade era político e cultural. O principal objetivo da reforma precisava ser a discussão das causas que permitiam a alguns alunos ingressar nas instituições superiores e excluíam outros jovens da mesma idade de possuírem igual oportunidade. Vieira Pinto apontou, como aspecto importante da reforma, a necessidade de estratégias para a maior democratização do ensino superior. Considerou indispensável uma mudança não somente na estrutura do sistema de ensino, mas, sobretudo, na oferta e propagação dessa educação, que deveria estar vinculada ao objetivo de superação das condições de exclusão, que advinham da insuficiente quantidade de vagas para as camadas populares e da ideologia propagada, que reafirmava e mantinha a elite na posição de maior acesso à cultura e à universidade. A educação superior necessitava contemplar uma formação crítica e emancipatória. Vieira Pinto exaltou a importância da atuação dos estudantes na luta pela profunda reforma universitária, conclamando processo de mudança no ensino superior.

Palavras-chave: História da Educação; Reforma do Ensino Superior; Álvaro Vieira Pinto.

\section{NOTES OF ÁLVARO VIEIRA PINTO FOR THE UNIVERSITY REFORM IN BRAZIL IN THE DECADE OF 1960}

\begin{abstract}
This article is a result of a study developed about debates that preceded the Reform of Higher Education, Law 5.540 of 1968, in which was possible to know the contributions of the educator Álvaro Vieira Pinto (1909-1987) in discussions about the situation and the role of universities in Brasil, as well as in the definition of proposals of changes and development of this educational system in 1960'. The text present the proposals of Vieira Pinto about the reform and organization of the Higher Brazilian Education based specially in analysis of his work A Questão da Universidade (1986) written in 1961, which approaches aspects of the existent and wanted model of university in the country in that moment. In the author's perspective, the problem of university was political and cultural. The main objective of the Reform would need to be discussing the causes that let some students be admitted in higher institutions and excluded other young with same age of having same opportunities. Vieira Pinto pointed as important aspect of Reform the
\end{abstract} Revista HISTEDBR On-line, Campinas, $n^{\circ}$ 53, p. 263-279, out2013-ISSN: 1676-2584 263 
necessity of strategies for democracy in higher education. He considered essential a change not only in structure of educational system, but, especially on the offering and spreading of this education that should be linked with the objective of overcoming of condition of excluded, that comes from the insufficient amount of vacancies to popular classes and the ideology spread that allowed the elite to remain on the position of accessing the culture and the university. The Higher Education would need to contemplate a free and critical formation. Vieira Pinto praised the importance of action of students in fight to deep university reform, calling for the process of changes in Higher Education.

Keywords: History of Education; Reform of Higher Education; Álvaro Vieira Pinto.

\section{Introdução}

Este artigo resulta de um estudo desenvolvido acerca dos debates antecedentes à Reforma do Ensino Superior, Lei $n^{\circ} 5.540$ de 1968, em que foi possível conhecer as contribuições do educador Álvaro Vieira Pinto (1909-1987) nas discussões sobre a situação e o papel da universidade no Brasil, bem como na definição de propostas para alterações e desenvolvimento desse sistema de ensino na década de 1960. O texto apresenta as proposições de Vieira Pinto sobre a reforma e organização do ensino superior brasileiro, baseando-se, em especial, na análise de sua obra A Questão da Universidade (1986) escrita em 1961, que aborda aspectos do modelo de universidade presente e almejado no país naquele momento.

A universidade brasileira tem sido objeto de debates e disputas desde a sua criação. A década de 1960 é relevante por acirrar essas lutas, permitindo aos estudantes e professores se posicionarem e traduzirem, na forma de propostas, um projeto de universidade que buscasse atender à população brasileira que se mantinha afastada de possibilidades de frequentá-la.

Muitas dessas demandas não foram alcançadas, todavia provocaram a necessidade de ampliação do acesso a esse nível de ensino, desencadeando reformas. A compreensão desse processo justifica a releitura de Vieira Pinto por sua ação marcante nesse cenário de questionamento do papel do ensino universitário.

$\mathrm{Na}$ década de 1960, o ensino superior no Brasil tornou-se tema de intensas discussões com o processo de análise e aprovação da Lei de Diretrizes e Bases da Educação (Lei $\mathrm{n}^{\circ}$ 4.024) no Congresso Nacional, sendo esta sancionada em dezembro de 1961, e com a posterior previsão de uma reforma na estrutura do ensino superior brasileiro, que foi instituída por intermédio da Lei $\mathrm{n}^{\circ}$ 5.540, de novembro de 1968. Nesse sentido, muitos intelectuais envolveram-se nos debates relativos à organização do ensino superior e ao papel da universidade na sociedade e no desenvolvimento nacional. Vieira Pinto enfatizou a reforma universitária como indispensável para o progresso. Apresentou como premissa o ideário de democratização das condições de acesso ao ensino superior. Em sua opinião, o ponto de partida para a compreensão da reforma universitária era considerar o direito das camadas populares à universidade:

O tema capital da reforma não consiste na organização do ensino para os elementos que ingressaram na universidade. Isto seria o simples aspecto didático. O principal está em discutir as causas que permitiram a esses 
alunos entrar nas escolas e excluíram os demais jovens da mesma idade de terem igual oportunidade. (VIEIRA PINTO, 1986, p. 20).

A seguir, são abordadas considerações sobre a questão universitária no Brasil na década de 1960 e a perspectiva de Vieira Pinto referente à reforma no ensino superior e à função social da universidade. $\mathrm{O}$ autor promoveu reflexões significativas, no que concerne à estrutura, organização e ao papel das universidades brasileiras com vistas à democratização do ensino e à formação das massas populares, denunciando o caráter seletivo e excludente da sociedade brasileira.

\section{Álvaro Vieira Pinto e o ideário de reforma universitária}

Álvaro Borges Vieira Pinto nasceu em Campos, Rio de Janeiro, em 11 de novembro de 1909. Formou-se em Medicina no ano de 1932, pela Faculdade Nacional de Medicina do Rio de Janeiro. Realizou os cursos de Física e Matemática na Universidade do Distrito Federal (UDF). Exerceu o ofício de professor, lecionou Lógica na Faculdade Nacional de Filosofia (FNFi) da Universidade do Brasil. (CPDOC - FGV, 2013, p. 1). Recebeu indicação de Alceu Amoroso Lima e recomendação de Leonel Franca para atuar na Faculdade de Filosofia, onde se tornou professor da Cadeira de História da Filosofia na Faculdade Nacional de Filosofia. (FREITAS, 1998). Tornou-se, em 1955, chefe do Departamento de Filosofia do Instituto Superior de Estudos Brasileiros (ISEB) e, em 1962, assumiu a direção executiva desse instituto. (CPDOC - FGV, 2013, p. 1).

A atividade no Instituto Superior de Estudos Brasileiros direcionou Vieira Pinto à compreensão da realidade nacional por meio de categorias filosóficas. Buscou constituir uma ideologia do desenvolvimento nacional sob a perspectiva da filosofia dialética. É desse período a edição das obras Consciência e Realidade Nacional ${ }^{3}$ (1960), Ideologia e Desenvolvimento Nacional (1960) e A Questão da Universidade (1962). (SAVIANI, 2002, p. 52).

Vieira Pinto foi cassado pelo Ato Institucional $n^{\circ} 1$ (AI-1), refugiou-se em Minas Gerais e, posteriormente, foi para o exílio, situação que o levou a morar na Iugoslávia e no Chile, exercendo atividades de pesquisador e professor. (CPDOC - FGV, 2013). No Chile, ele produziu diversos trabalhos, dentre os quais El Pensamento Crítico em Demografia, Ciência e Existência e Sete Lições sobre Educação de Adultos ${ }^{4}$. Estes dois últimos trabalhos foram publicados no Brasil, respectivamente, nos anos de 1969 e 1982. (SAVIANI, 2002). Vieira Pinto voltou ao Brasil em dezembro de 1968, na época em que foi estabelecido o Ato Institucional $\mathrm{n}^{\mathrm{o}}$ 5. Ao retornar ao Rio de Janeiro, pôde observar tristes consequências dessa determinação. Ele se recolheu na residência, sabe-se que no período de 1968 a 1987, produziu e reviu textos e livros, conservando trabalhos que abordavam os temas Educação, Ética e Tecnologia. (FREITAS, 1998). Na década de 1970, o autor traduziu para a editora Vozes obras de autores importantes como Georg Lukacs e Claude Lévy-Strauss. Álvaro Vieira Pinto faleceu no Rio de Janeiro em 11 de junho de 1987. (CPDOC - FGV, 2013).

No início da década de 1960, empenhou-se nas discussões sobre o sistema do ensino superior nacional. Em sua obra A Questão da Universidade, discutiu aspectos a serem considerados para uma efetiva reforma universitária no período. Para ele, a reforma do ensino superior precisava promover mudanças decisivas em benefício de toda a população brasileira. Referia-se à universidade, levando em consideração a existência de 
uma multiplicidade de instituições e organismos escolares, ou seja, os diversos aspectos referentes à antiguidade, estrutura e às condições materiais que influenciam a organização e o ensino ofertado no contexto universitário.

O livro A Questão da Universidade trata-se de uma conferência proferida em Belo Horizonte e que, posteriormente, a diretoria da União dos Estudantes (UNE) solicitou a publicação. Vieira Pinto, na ocasião, analisou a situação da organização do ensino superior brasileiro, contemplando o ideário de Reforma e o papel das universidades na sociedade, bem como expressou ser possível a contribuição da ação do movimento estudantil na luta por melhores condições de oferta do ensino universitário na realidade nacional. Expressou, desse modo, uma perspectiva progressista em contraposição à reacionária; suas proposições originais expressaram o ideário de mudança para a emancipação e maior participação do povo na vida política e social. Na análise de Saviani (2002, p. 54),

A Questão da Universidade constituiu, embora de forma serena e refletida, um libelo, de certo modo violento ao elitismo, conservadorismo, arcaísmo e alienação das estruturas universitárias a serviço da dependência cultural imposta pelos interesses dos grupos que dominavam economicamente e, por consequência, impunham seu poder ao conjunto da sociedade. Escrito em 1961, situou-se no bojo do processo que então se caracterizava como pré-revolucionário. [...]. Álvaro Vieira Pinto se posicionou resolutamente ao lado das forças revolucionárias e foi à luz dessa posição, filosoficamente fundada na perspectiva da dialética social, que ele desenvolveu as reflexões agudas, lúcidas e penetrantes sobre a questão da reforma universitária como uma dentre as diversas reformas de base pelas quais lutavam as forças progressistas naquele momento da vida do País.

A partir de 1960, nota-se intensa expansão quantitativa do ensino superior brasileiro, contudo essa realidade não fora suficiente para atender toda demanda. No decorrer da década de 1950, em especial no governo de Juscelino Kubitschek (1956-1961), no setor do mercado de trabalho, ampliou-se a busca por pessoas com alto nível de escolarização, fato que, aliado ao crescente desejo dos indivíduos em alcançar posição elevada na sociedade, tornou a expansão do ensino superior indispensável. Houve crescimento da rede escolar de $2^{\circ}$ Grau e o consequente aumento de candidatos que passaram a almejar a universidade. O impasse é que não havia vagas disponibilizadas pelos exames vestibulares suficientes para atender tais necessidades. (FAUSTO, 2007).

A segunda metade da década de 1950 tornou-se conhecido como período de ouro da economia. Houve a tentativa de conciliação do modelo nacional-desenvolvimentista ao modelo econômico de substituição de importações. A abertura ao capital estrangeiro foi um fator considerado importante para o desenvolvimento e fortalecimento da indústria nacional. Com a expansão industrial, as possibilidades de emprego aumentaram, entretanto lucros maiores concentraram-se em setores minoritários internos e, em especial, externos, com a predominância do capital estrangeiro. Fausto (2007, p. 427) pontua que, entre 1955 e 1961, “[...] o valor da produção industrial, descontada a inflação, cresceu em 80\%, com altas porcentagens nas indústrias do aço (100\%), mecânicas (125\%), de eletricidade e comunicações $(380 \%)$ e de material de transporte $(600 \%)$ ".

Assim, gradativamente, aumentaram-se as pressões e solicitações para a ampliação do ensino superior brasileiro, havendo crescimento de instituições privadas nessa área de ensino. Freitas e Biccas (2009, p. 265) destacam que, no período de 1945 a 1964, “[...] 
manifestaram-se muito claramente as ambigüidades das políticas públicas para o ensino superior. De um lado, ocorreu um grande crescimento do setor privado, de outro, estabeleceu-se o processo de federalização de faculdades estaduais e privadas reunidas em universidades".

Nesse contexto de crescimento do número de instituições de ensino superior e de luta pela democratização das condições de acesso aos bancos universitários, Vieira Pinto se destaca pelas análises referentes ao sistema de ensino superior brasileiro e pela defesa por uma educação universitária de qualidade, não seletiva e não desigual na oportunidade de acesso e formação. Ele propôs definições e passos para uma profunda reforma da universidade.

As contribuições do autor se estendem à análise da realidade social brasileira. Saviani (2002) comenta que a influência de Vieira Pinto no campo educacional derivou de seu empenho em compreender a realidade nacional. Ele buscou constituir a teoria do desenvolvimento nacional, que colaborou para a formulação e propagação da ideologia do nacionalismo desenvolvimentista, presente no país nas décadas de 1950 e 1960. Isso contribuiu, por sua vez, com os movimentos educativos, como as tendências Educação Popular e Pedagogia da Libertação. Paulo Freire, em suas obras Educação como Prática da Liberdade e Pedagogia do Oprimido, expressa conceitos discutidos por Vieira Pinto, registrando, assim, a importância de sua obra. (SAVIANI, 2002).

Vieira Pinto (1986), ao abordar assuntos sobre a reforma universitária, definiu, a princípio, que era urgente reformar a universidade, mas era preciso avaliar que esse dilema constituía-se em uma faceta particular do problema de reforma geral da sociedade brasileira. Desse modo, apontou, como aspecto principal da reforma, a necessidade de estratégias para a maior democratização do ensino superior. A exclusão de uma imensa parcela da população brasileira na educação superior era um problema que precisava ser solucionado ao lado da superação das condições de dominação cultural à qual a sociedade estava subordinada.

Em sua perspectiva, a universidade precisava passar por um processo de reforma por se constituir em peça fundamental da estrutura arcaica que mantinha condições sociais reacionárias de exclusão social. A universidade, historicamente, havia assumido o papel de fomentar ideologias. Era preciso que fosse modificada não apenas a estrutura de seu sistema, mas também as condições de ensino, que precisava estar comprometido com a formação crítica e emancipatória dos alunos para ação política e social. Assim, defendeu que a universidade precisava ser transformada em sua essência, nos mecanismos que promovia a dependência e alienação cultural do país.

É neste sentido que se estabelece no presente momento o problema da reforma da universidade: trata-se de transformá-la não na superfície, não na superestrutura pedagógica, no cerimonial didático, nas qualificações jurídicas, no enriquecimento de recursos financeiros, no aprimoramento das instalações materiais levadas às vezes à suntuosidade, pois tudo isto, agora se compreende, por mais útil que seja é secundário. Trata-se de transformá-la na essência, isto é, de fazê-la deixar de ser um centro distribuidor da alienação cultural do país, para convertê-la no mais eficaz instrumento de criação de nova consciência estudantil direta e exclusivamente interessada em modificar a estrutura social antiga e injusta, substituindo-a por outra humana e livre. (VIEIRA PINTO, 1986, p. 15). 
Para o autor, o problema da universidade era político e cultural. Os dirigentes atuantes no ensino superior eram representantes da elite. Essa classe privilegiada mantinha o domínio ideológico e a sua condição de existência, impossibilitando que a camada pobre da população usufruísse do ensino superior. A universidade, naquele momento, não se caracterizava como democrática e sim exclusiva para os ricos, afirmava:

Assim procedendo, cremos ter razão em apresentar a seguinte definição da essência da universidade no Brasil, atualmente: a universidade é uma peça do dispositivo geral do domínio pelo qual a classe dominante exerce o controle social, particularmente no terreno ideológico, sobre a totalidade do país. Se tal é a essência da universidade, desde logo se vê que o problema de sua reforma é político e não pedagógico. Este último aspecto existe, é claro, mas se mostra secundário, pois só se apresentará na forma em que pode e deve ser resolvido, depois que tiver sido decidido politicamente o destino da universidade e sua participação no projeto de transformação social empreendido pela comunidade. (VIEIRA PINTO, 1986, p. 19).

As discussões de Vieira Pinto, na perspectiva de Saviani (1986), expressam-se como revolucionárias naquele contexto. Apresentam reflexões sobre o problema das relações entre universidade e sociedade, bem como sobre a responsabilidade e o compromisso sociais para com os interesses da classe trabalhadora, que o ensino superior necessita assumir. Suas posições estavam alinhadas às reformas de base pelas quais lutavam as forças progressistas brasileiras. Cumpre ressaltar que Vieira Pinto contribuiu significativamente com discussões sobre a realidade social em seus diversos aspectos. Dias e Araújo (2002, p. 103) comentam que "[...] a sua preocupação era com a superação do estágio atrasado de desenvolvimento histórico-social, político-econômico cultural e material em que o país se encontrava. Um dos caminhos para que isso acontecesse seria a mudança no desenvolvimento nacional e na educação." Sua obra, portanto, revelava-se fundamental para os profissionais comprometidos com a educação e as classes populares.

A educação das massas tornava-se prioridade, conforme enfatizou Vieira Pinto (1986), ao analisar a situação do ensino superior no início da década de 1960. O princípio fundamental da reforma universitária não consistia na organização do ensino para os indivíduos que já estavam na universidade; este era um aspecto didático a ser solucionado por outros meios. O principal objetivo da reforma era discutir as causas que permitiam a alguns alunos ingressar nas instituições superiores e excluíam outros jovens da mesma idade de possuírem igual oportunidade. A questão universitária se referia à questão da democratização das condições de acesso ao ensino superior. A Reforma Universitária precisava inicialmente se referir aos alunos que não puderam entrar na universidade, e depois lidar com os aspectos internos da oferta desse ensino, como os didáticos, jurídicos, éticos e econômicos da realidade universitária.

A democratização do ensino superior foi enfatizada nas décadas de 1950 e 1960 por diversos intelectuais que defendiam a maior participação do Estado nos assuntos relativos à educação. Anísio Teixeira (1994), nos anos de 1950, realçou a afirmação de que a educação não era privilégio e sim direito de todos. A União precisava atuar na assistência financeira e técnica das escolas. $O$ ensino médio devia estruturar condições para o prosseguimento no ensino superior. Em sua concepção, a educação superior não poderia estar desvinculada da noção de um sistema nacional de ensino, precisava também ser alvo de atenção do Estado. 
Com efeito, embora as instituições escolares tenham seus objetivos próprios, todas elas se articulam num sistema contínuo de educação, em que os graus mais altos influem na organização e sentido dos menos altos, determinando isto que o ensino médio condicione o primário, e o superior condicione o médio. (TEIXEIRA, 1994, p. 67-68).

A educação deveria mudar em todos os níveis sob a tutela estatal, visto que os diferentes níveis se articulam. Desta forma, o ensino universitário colocava-se como questão para ele, bem como para outro intelectual: Florestan Fernandes. Este, na segunda metade da década de 1960, pronunciou diversas conferências, enfatizando a reforma universitária como imprescindível e urgente na sociedade brasileira. Para tanto, realizou um estudo detalhado sobre dados de matrículas nos diferentes níveis de ensino no Brasil e constatou que, embora fosse possível perceber que historicamente houve notável crescimento no número de matrículas no ensino superior, a quantidade de vagas era insuficiente naquele momento. Fernandes argumentou que pequena parcela da população brasileira alcançava o ensino superior; faltavam instituições e cursos superiores que atendessem a demanda; o ensino superior privilegiava a formação de poucos profissionais liberais; havia limites na função de preparar a massa de profissionais, conforme as necessidades sociais; a estrutura e o ensino universitário não correspondiam a certa homogeneidade e universalidade no país.

\begin{abstract}
Os dados apresentados indicam que o Brasil enfrenta vários problemas graves em relação à organização, expansão e aproveitamento do ensino superior. Em primeiro lugar, estão os problemas especificamente quantitativos. A proporção de pessoas com formação superior, na população escolarizada e no conjunto da população, é quase ínfima. Em segundo lugar, estão os problemas de natureza pedagógica. Em virtude da predominância dos interesses econômicos, sociais e políticos de elites culturais ralas e egoísticas, o ensino superior foi praticamente confinado à função de preparar profissionais liberais. Sua diferenciação e expansão ficou contida, mesmo depois da revolução de 1930 e do crescimento acelerado recente da rede escolar, pela pressão da procura de pessoal de nível superior. Em terceiro lugar, estão os problemas sociodinâmicos. A sociedade brasileira não conseguiu imprimir ao desenvolvimento do ensino um mínimo de homogeneidade e de intensidade. As flutuações regionais e, principalmente, os interesses de classe introduziram graves distorções na mobilização dos recursos educacionais ao nível do ensino superior. (FERNANDES, 1975, p. 48-49).
\end{abstract}

As críticas ao ensino superior e a necessidade de reforma da universidade tornavase problema crucial à sociedade brasileira. Sobre esta questão, Vieira Pinto, em 1961, destacou ser preciso considerar que o sistema da universidade não estava articulado de modo a oferecer a toda população brasileira oportunidade de educação superior, já que as massas trabalhadoras eram privadas das contribuições desse ensino. A universidade consistia em um instrumento eficiente para assegurar o comando ideológico da classe dominante, pois além de impossibilitar a todos o acesso à formação superior, estava incumbida de produzir os próprios esquemas intelectuais de dominação; a ciência produzida no campo não se contrapunha aos mecanismos de exclusão. A universidade formava os representantes políticos da classe dominante. A universidade não pertencia ao 
povo, não era pensada para o povo; assim, não alcançava as necessidades gerais das massas trabalhadoras. Era preciso mudar essa situação, e a reforma poderia ser um meio de transformações significativas dessa realidade.

\section{A Questão Universitária e a Função Social da Universidade na Perspectiva de Álvaro Vieira Pinto}

Álvaro Vieira Pinto denunciava que a universidade no Brasil no período estava assumindo a função essencial de garantir a autorreprodução da classe dominante, pois era no espaço universitário que se encontravam as condições ideais para a classe dominante se desenvolver, uma vez que o privilégio de acesso ao ensino superior estava sendo alcançado pela elite e não pelo povo. A universidade incutia a mentalidade de que a aquisição da cultura era mérito e algo que se distinguia do povo; assim, a instituição expulsava o povo do direito à cultura (VIEIRA PINTO, 1986). Desse modo, destacou que

A universidade, por suas relações com a classe dominante, exerce sobre o resto do país efeito pernicioso, ocultador, pois prepara e distribui os instrumentos ideológicos que conturbam a consciência nacional, e não se dedica ao que seria sua tarefa meritória e própria - a de preparar o espírito das jovens gerações para o melhor conhecimento do Brasil, dos seus problemas e dos meios de resolvê-los. (VIEIRA PINTO, 1986, p. $35)$.

Segundo o autor, a universidade exercia o papel alienante de converter os jovens críticos das classes dominadas aos interesses das classes dominantes, impossibilitando-os de adquirir consciência de sua própria condição de classe. Por outro lado, não permitia condições aos professores para agirem em contrassenso aos processos de exclusão universitária:

O papel alienante da universidade é duplo: aliena a consciência da classe dominada, no sentido, como vimos, de impedi-la de construir um tesouro cultural autêntico, que exprima seus próprios interesses de classe submissa e a auxilie a libertar-se das suas servidões; mas, ao mesmo tempo, aliena também a consciência da classe professoral, no sentido de que a faz tributária da cultura do país metropolitano dominante. (VIEIRA PINTO, 1986, p. 38).

Assim, Vieira Pinto afirmou que a universidade teoricamente trabalhava com a universalidade do ensino, mas, na prática, essa realidade não ocorria, uma vez que, nas sociedades divididas em classes, a cultura necessariamente possui base de classe. Sendo assim, no âmbito universitário, a cultura protegida e defendida era a cultura correspondente à classe a qual se mantinha dominante, ou seja, a elite. Considerar o plano universal exigia atender o interesse do povo brasileiro em sua maior amplitude.

A universidade tem realmente por objetivo exprimir o conhecimento no plano universal, mas só poderá fazer quando se tiver convertido ao ponto de vista dos reais interesses do povo brasileiro, pois só então haverá adquirido a condição de identificação com a realidade concreta e única, 
em virtude da qual o Brasil terá acesso ao campo da autêntica universalidade. Compreenderá que o "universal" não é o modo de pensar de ninguém, mas exatamente o de alguém sobre a totalidade da realidade, e quando se diz alguém, a palavra significa alguém que está situado no tempo e no espaço que pertence a tal país, a tal classe, etc. Somente quando tiver por finalidade cooperar para a realização dos fins históricos do nosso povo, a universidade, pela obra dos seus pensadores, adquirirá o fundamento necessário para emitir juízos universais sobre a realidade da nação brasileira e sobre o mundo externo, metropolitano ou atrasado, onde nos situamos. (VIEIRA PINTO, 1986, p. 46).

Em Consciência e Realidade Nacional (1960b), o autor registrou que a educação não era desprovida da consciência de classe. Percebia-se que os interesses da classe dominante prevaleciam na direção da educação. Era importante, em contraposição, a força do movimento organizado das massas trabalhadoras em favor da transformação das condições reacionárias.

A função proveitosa que a universidade deve desempenhar terá de lhe ser imposta de fora para dentro, pelas forças políticas, particularmente as massas trabalhadoras organizadas, que, ao impulsionar a alteração da sociedade, a transformação em órgão cooperante no desenvolvimento do País. [...] A escola não existe desligada da consciência das classes que legislam sobre a educação, é sempre aquilo que as camadas dirigentes acham que deve ser. Não há "educação" em caráter abstrato, e não ser na fala dos publicistas simplórios. Há sempre "uma educação", aquela que concretamente se cumpre no âmbito social, por serem tais as condições de seu exercício e as ideias que a orientam. (VIEIRA PINTO, 1960b, p. 503-504).

Desta forma, avaliava que a burguesia era a classe dominante da sociedade brasileira e, em geral, era a que predominava no meio universitário. Por essa razão, o autor, em A Questão da Universidade (1986), destacou que a autonomia da universidade precisava ser limitada, era preciso apenas admitir a total autonomia da universidade quando esta pertencesse ao povo. Em sua perspectiva, naquele momento, a universidade apresentava um sistema defensivo e opressivo que impedia a entrada da massa estudantil. Em geral, as condições de ingresso na universidade excluíam a entrada de indivíduos da baixa classe média e quase totalmente da classe trabalhadora. Era preciso que considerassem a reforma universitária pelo aspecto social. A reforma deveria ser implantada com vistas ao público que precisava ser atendido pelo ensino superior, visando à formação da massa trabalhadora das classes desprivilegiadas que apresentava a real necessidade de preparação para vida política e social.

A reforma da universidade tem de ser considerada como ato social, destinado a anular um passado de privilégios, a situação cultural de alienação, a pretensão da aristocracia doutoral, só justificados enquanto o país vivia a fase de sua total dependência e opacidade intelectual, mas agora em franca superação por efeito das transformações materiais ocorridas e das lutas sociais em curso. Para enfrentar o problema de que nos ocupamos, decisiva é a pergunta inicial. Pois, pela maneira como é formulada, já se define a possibilidade de ser correta ou incorretamente 
analisado tudo o mais que dela decorre. Para nós, a pergunta inicial justa consiste em indagar "para quem?" é preciso fazer a reforma da universidade. Só depois dela respondida adquire sentido passar à pergunta imediata: "que universidade" se deve instituir. Por fim, no terceiro momento tem cabimento indagar "como organizá-la". Eis aí delineada a marcha da nossa reflexão teórica sobre o assunto. (VIEIRA PINTO, 1986, p. 71, grifos do autor).

Sendo assim, Vieira Pinto ressaltou que a universidade precisava servir à classe trabalhadora e não continuar a serviço dos interesses da classe dominante. A reforma precisava fornecer condições para que a universidade passasse ao serviço das massas trabalhadoras em contribuição à promoção da consciência e ao desenvolvimento social.

Freitas (2006, p. 84) apresenta a reflexão que, em Vieira Pinto, a consciência crítica é um "patrimônio" das massas; a "[...] consciência torna-se crítica quando o homem passa a ter clareza que 'deve' mudar a realidade", o "homem do povo", como o trabalhador manual, possuía uma percepção diferenciada da realidade, porém não inferior, em termos de qualidade, à percepção e visão de mundo expressas pelas classes dominantes. Um processo educativo pode contribuir para a fomentação da noção de "dever fazer", em conjunto com o entendimento do "porquê" e "como" mudar a realidade. O autor assinala que, para "[...] Vieira Pinto, a massa era, na realidade, a grande porta-voz da consciência crítica da nação. Isso porque, somente a massa, diante da história, revelava-se como portadora do interesse pela mudança." (FREITAS, 2013, p. 175).

Em Sete Lições Sobre Educação de Adultos (1997, p. 63), ao discutir aspectos da concepção crítica da educação, ressaltou o seu autor que o educando não pode ser considerado um "desconhecedor absoluto". Nesse sentido, o adulto analfabeto é um homem culto no aspecto objetivo, não idealista, do conceito de cultura. A instrução formal, como a alfabetização, deve ser desenvolvida a partir da base cultural que o educando possui, relacionando-se reflexivamente com o conhecimento material e cultural da sociedade. Em Consciência e Realidade Nacional (1960a), o autor enfatizou que a cultura não é simples acumulação de qualquer espécie de saber, mas a assimilação do saber, sob perspectiva consciente, dos fundamentos e das exigências que permitiram a incorporação do conhecimento de uma época e o pensar como saber atual. Nesse sentido, apresentou a seguinte definição:

Culto é o homem que aceita realizar uma incumbência exigida pela comunidade a que pertence e se preparou devidamente para isso, munindo-se dos conhecimentos necessários. Não é de modo algum o que se adornou de leituras clássicas, que perambulou por museus estrangeiros ou absorveu alguma disciplina científica por prazer ou por orgulho em possuí-la. Tudo isso pode fazer parte da cultura, mas não a define; tudo depende do seu sentido que recebe daquele que se mune das artes, das letras e da ciência. (VIEIRA PINTO, 1960a, p. 118).

À educação cabia o progresso da consciência, que, por sua vez, poderia influir no desenvolvimento nacional. Na perspectiva de Vieira Pinto (1960a, p. 118), “[...] a educação não precede o processo de desenvolvimento, acompanha-o contemporâneamente". Sendo assim, entre a educação e o desenvolvimento, havia certa tensão dialética que os determinava mutuamente. Contudo, era preciso considerar que a realidade suscitava o conteúdo da educação que convém ao momento histórico. O processo 
de desenvolvimento estabelecia os conteúdos convenientes a constituir a matéria da educação, caracterizando-os como autênticos da cultura. Mas a educação, por outro lado, reagia no processo em curso, podendo torná-lo tardio ou acelerá-lo. A educação adequada e oportuna precisava ser conduzida pelos que possuíssem consciência crítica do processo da realidade; portanto, era a que permitia a uma consciência crítica suscitar a formação de outra consciência crítica. Desse modo, argumentou que:

Educar para o desenvolvimento não é tanto transmitir conteúdos particulares de conhecimento, reduzir o ensino a determinadas matérias, nem restringir o saber exclusivamente a assuntos de natureza técnica; é, muito mais do que isto, despertar no educando novo modo de pensar e de sentir a existência, em face das condições nacionais com que se defronta; é dar-lhe a consciência de sua constante relação a um país que precisa do seu trabalho pessoal para modificar o estado de atraso; é fazê-lo receber tudo quanto é ensinado por um novo ângulo de percepção, o de que todo o seu saber deve contribuir para o empenho coletivo de transformação da realidade. Não há nisso uma visão idealizada do processo de desenvolvimento, mas o reconhecimento de que a lógica a ele imanente demanda uma consciência que o represente e uma vontade que se mova conforme as sugestões e exigências dele partidas. (VIEIRA PINTO, p. 1960a, p. 121).

A elaboração da ideologia do desenvolvimento nacional era influenciada pela consciência gerada do trabalho. No processo de aquisição de consciência, o trabalho era importante. Freitas (1998) comenta que Vieira Pinto considerou que o trabalho poderia promover o encontro objetivo entre a realidade e o homem, era uma ação transformadora, revelava a realidade e sintetizava a história dos homens (FREITAS, 1998). Vieira Pinto (1960b) asseverava que o desenvolvimento é sempre acompanhado de um processo de transformação qualitativa da consciência nacional. A educação, sendo um significativo processo de expansão da consciência social útil, precisava ser popular. O desenvolvimento influía no processo de consciência, sendo este acelerado pela educação, mas, para tanto, era preciso, nas palavras de Vieira Pinto (1960b, p. 502), que “[...] a educação vise à totalidade das massas trabalhadoras e se descaracterize cada vez mais como privilégio das elites".

Em A Questão da Universidade (1986), ele enfatizou que a reforma universitária necessitava consistir na reforma dos conteúdos de classe da universidade, de maneira a permitir às massas ingressarem no domínio da cultura a serviço dos próprios interesses e não a favor dos interesses da classe dominante. Em sua concepção, os estudantes, em especial, tinham um papel importante no processo transformador da universidade.

É importante destacar que os estudantes marcaram presença na movimentação em torno da reforma universitária na década de 1960. Veiga (1985) aponta que, nos anos iniciais de 1960, os estudantes questionaram o sistema de cátedras, solicitaram representação estudantil e a atuação da comunidade universitária no envolvimento com as classes subalternas, reivindicaram a extinção do vestibular e a honestidade na administração dos recursos da educação. No período de 1961 a 1963, a União Nacional dos Estudantes (UNE) realizou três seminários nacionais referentes à reforma universitária: na Bahia em 1961, no Paraná em 1962 e em Minas Gerais em 1963.

O I Seminário Nacional de Reforma Universitária, realizado em Salvador, em maio de 1961, promovido pela União Nacional de Estudantes, contou com a participação de 
estudantes, professores, estudiosos e autoridades. Nesse evento, foi aprovada uma Declaração, que dentre seus tópicos, destacava a premissa de que a Reforma precisava visar à democratização da universidade e que a participação estudantil era essencial para a constante renovação do ensino e de valores da universidade, sendo preciso, no âmbito dos órgãos técnico-administrativos, comissões e departamentos da universidade, promover a participação dos discentes, docentes e profissionais com direito à voz e ao voto. O sistema de cátedras, a carreira universitária e a formação dos professores universitários foram postos em questão, sendo proposta mudança na estrutura vigente, com a implantação do sistema de departamentos como unidades constituintes de faculdades e institutos. (I SEMINÁRIO NACIONAL..., 1961).

Fávero (2006) comenta que, dos Seminários e das propostas dos estudantes, por intermédio da UNE, é possível perceber a posição de combate ante as características arcaica e elitista das universidades. Nos seminários, foram abordadas questões importantes, tais como: “[...] a) autonomia universitária; b) participação dos corpos docente e discente na administração universitária, através de critério de proporcionalidade representativa; c) adoção do regime de trabalho em tempo integral para docentes; d) ampliação da oferta de vagas nas escolas públicas; e) flexibilidade na organização de currículos. [...]" (FÁVERO, 2006, p. 29). Freitas e Biccas (2009, p. 266) asseveram que o movimento estudantil teve "[...] um papel fundamental na luta pela defesa da extinção da cátedra, indicando a criação dos departamentos, inspirado no modelo norte-americano, idealizados como possibilidades de práticas universitárias que integrassem ensino, pesquisa e extensão".

É importante frisar que a Lei de Diretrizes e Bases da Educação Nacional, Lei $n^{\circ}$ 4.024, de dezembro de 1961, trouxe, em seu artigo 78, abertura à participação da representação estudantil nos conselhos universitários, com a seguinte definição: "O corpo discente terá representação, com direito a voto, nos conselhos universitários, nas congregações, e nos conselhos departamentais das universidades e escolas superiores isoladas, na forma dos estatutos das referidas entidades". (BRASIL, 1961, p. 243). O movimento estudantil contribuiu para a tomada de consciência nacional acerca dos problemas da universidade. Com o golpe militar de 1964, algumas ações desse movimento passaram a ser restringidas.

Na obra A Questão da Universidade, de 1961, Vieira Pinto destacou a possibilidade de haver uma espécie de direção conjunta entre professores e alunos no âmbito dos processos decisórios da organização das instituições de ensino. Era preciso que a classe estudantil e os professores tivessem participação ativa na gestão dos cursos de ensino superior, sendo consideradas as opiniões dos alunos e professores na constituição do ensino.

Cogoverno - Esta talvez seja a mais "escandalosa" das medidas propostas e seguramente a que mais resistências despertará. No entanto, parece-nos essencial para caracterizar a mudança qualitativa na essência da universidade. Se, conforme dissemos, esta deve consistir na mudança dos conteúdos de classe da universidade, com a entrega da instituição ao povo, aí representado pelas massas trabalhadoras estudantis, não se compreende a persistência do sistema de domínio exclusivo do grupo docente na administração, direção e controle das escolas superiores. A democratização da universidade deve exprimir-se no estabelecimento do cogoverno docente-discente em todas as instâncias decisórias; departamentos, conselhos departamentais e técnico-administrativos, 
congregações, conselhos de curadores, direções, conselhos universitários e quaisquer outros órgãos que representem poder dirigente sobre assuntos internos da universidade. Em todas estas instâncias, o corpo discente precisa estar representado por um número de delegados igual ao dos docentes, com a mesma dignidade e idêntico poder de decisão pelo voto. Esta medida é capital porque determina a transformação da classe estudantil, até agora tutelada, em responsável. Torna-a, igualmente, mais representativa dos interesses populares no interior da universidade. (VIEIRA PINTO, 1986, p. 98-99).

A participação dos estudantes na organização das instituições universitárias foi decisivamente apoiada pelo movimento estudantil. A União Nacional dos Estudantes, no âmbito da campanha acerca da Reforma Universitária, defendeu a participação do corpo discente nos órgãos diretores das escolas superiores e da universidade. Propuseram, por intermédio de um manifesto direcionado aos estudantes e ao povo, um terço de participação dos alunos na decisão de escolha da direção da universidade. Representação e participação ativa do corpo discente nos conselhos universitários. Argumentavam que os Conselhos Universitários eram compostos por dois representantes (professores) por faculdade e solicitavam que, para cada escola, o corpo discente fosse representado na pessoa de um estudante. A proposta foi intensamente debatida na imprensa, nas assembleias universitárias e no Conselho Federal de Educação. (PARTICIPAÇÃO DISCENTE..., 1962).

O sistema de cogoverno argumentado por Vieira Pinto correspondia, naquele momento, à noção de maior democratização no âmbito da gestão das instituições de ensino superior escolar. $\mathrm{Na}$ atualidade, corresponde à concepção de gestão democráticoparticipativa, que, segundo Libâneo, Oliveira e Toschi (2009), segue o princípio de que todos dirigem e são dirigidos, todos avaliam e são avaliados, consiste na atividade coletiva que implica a participação e objetivos comuns. A participação possibilita o envolvimento de todos os integrantes da instituição no processo de tomada de decisões e no funcionamento da organização escolar. Espera-se relação orgânica entre a direção e a participação dos membros da comunidade escolar, no envolvimento da comunidade no processo escolar. Vieira Pinto pontuou a importância da participação dos estudantes, por intermédio da UNE, nas discussões sobre a reforma universitária. O autor, em sua obra $A$ Questão da Universidade, propôs que a UNE promovesse, como resultado de seminários nacionais, a organização de uma comissão composta exclusivamente por estudantes para a elaboração de um projeto de reforma sob a perspectiva dos estudantes.

\section{Considerações finais}

Álvaro Viera Pinto defendeu a ideia de que a universidade precisava ser do povo e não da elite. A universidade representava a suprema instância criadora do saber e organizadora do fecundo trabalho do povo. A reforma precisava consistir na modificação da estrutura universitária, de maneira a permitir às pessoas o acesso à aquisição de cultura para participarem nas instâncias sociais. A universidade não mudaria a essência por intermédio da modificação da organização, ela se transformaria, sobretudo, por meio da mudança do conteúdo de classe. O objetivo real da reforma universitária precisava ser de alteração das relações externas da universidade. Nas palavras do autor, era necessário 
desligar a universidade da vassalagem à classe dominante e direcioná-la completamente a serviço do povo, da massa trabalhadora.

As discussões de Vieira Pinto referentes à reforma universitária inserem-se historicamente no contexto de debates em torno da elaboração da primeira Lei de Diretrizes e Bases da Educação Nacional (Lei. 4.024/61). De acordo com Romanelli (1978), não houve mudanças na estrutura tradicional do ensino superior após a efetivação da LDBN. O maior progresso da Lei foi a expressão de um grau de descentralização. O Conselho Federal de Educação, em 1962, definiu a possibilidade de os Estados e os estabelecimentos anexarem disciplinas optativas ao currículo mínimo, sendo esta iniciativa um progresso em matéria de legislação, embora, na prática, as escolas acabassem compondo o currículo a partir de recursos materiais e humanos de que dispunham.

Conforme anunciado, a Lei de Diretrizes e Bases da Educação Nacional previu que o corpo discente tivesse representação com direito a voto na universidade. Essa premissa fora enaltecida pelo movimento estudantil, que destacou que a participação dos estudantes, na definição da LDB, “[...] longe de agravar o antagonismo entre mestres e discípulos, foi uma séria tentativa de integração dos pólos dinamizadores da cultura [...]”, um esforço para a superação de crises no sistema vigente. A partir disso, era preciso regulamentar a participação estudantil. (PARTICIPAÇÃO DISCENTE..., 1962, p. 203). O autor exaltou a importância da atuação dos estudantes na luta pela profunda reforma universitária. Cumpre destacar que com o movimento militar, iniciado em 1964, houve cerceamento da iniciativa dos estudantes e das classes trabalhadoras na sociedade brasileira; buscou-se controlar focos de resistências por intermédio de estratégias repressivas, restringindo, desse modo, a mobilização estudantil.

As análises e proposições sobre o ensino superior, desenvolvidas por intelectuais no início da década de 1960, fomentaram intensos debates que antecederam a resolução da reforma advinda com a Lei $\mathrm{n}^{\circ}$ 5.540. Segundo Morosini $(2005$, p. 313), “[...] a política educacional superior constituiu o período de 1945-64 como uma fase de construção do próximo período, que se instaura com a reforma universitária de 1968". Nessa fase, a modernização do ensino superior se processava. A modernização em especial se caracterizava pela busca da força de trabalho de nível universitário para, de um lado, atender ao capital monopolista, e de outro, atender aos anseios de mobilidade social das camadas médias.

Vieira Pinto contribuiu para a definição de propostas para a reforma e o desenvolvimento do ensino superior nacional. Para isso, discutiu aspectos políticos e sociais da universidade, destacando o papel dessas instituições na formação e conscientização crítica do cidadão e da classe trabalhadora brasileira. Em sua perspectiva, o ensino superior precisava ser democratizado. Enalteceu o ideário de mudança não somente na estrutura do sistema de ensino, mas, em especial, na oferta e propagação dessa educação, que deveria estar vinculada ao objetivo de superar as condições de exclusão, as quais advinham da insuficiente quantidade de vagas para todos e da ideologia propagada, que reafirmava e mantinha a elite na posição de maior acesso à cultura e ao nível de ensino superior. A educação superior precisava contemplar uma formação crítica e emancipatória.

A Lei $n^{\circ}$ 5.540, instituída em 1968, não ocasionou a transformação do sistema de ensino superior existente. A democratização no ensino brasileiro e a educação popular foram ideários defendidos por intelectuais em outras ocasiões pós-reforma. No que tange à Lei $\mathrm{n}^{\mathrm{o}} 5.540$ (BRASIL, 1968), é interessante frisar que enalteceu o objetivo do ensino superior em se preocupar com a pesquisa, o desenvolvimento das ciências, letras e artes e a formação de profissionais de nível universitário. Costa (1991) apresenta a reflexão de que a 
reforma universitária de 1968 adequou-se ao projeto hegemônico de classe, sendo que a principal mudança ocorreu no nível do ensino privado, com o apoio do governo federal, por meio do Conselho Federal de Educação (CFE). Houve a proliferação de novos cursos com o pretexto de atender a demanda, contudo não atendiam aos interesses da classe trabalhadora, bem como se distanciavam dos apontamentos de Vieira Pinto sobre a universidade que o Brasil precisava construir em meados do século XX.

\section{Referências}

BRASIL. Lei no 5.540 (de 28 de novembro de 1968). Brasília, DF, 28 nov. 1968. Disponível em: <http://www.planalto.gov.br/ccivil_03/leis/L5540.htm>. Acesso em: 22 jan. 2013.

BRASIL. Lei de Diretrizes e Bases da Educação Nacional (Lei no 4.024) (de 20 de dezembro de 1961). In: VILLALOBOS, João Eduardo Rodrigues. São Paulo: Editora da Universidade de São Paulo, 1969. p. 225-252.

COSTA, Alexandre Bernardino. Lei n. 5.540/68 - A Reforma do Ensino Superior: um projeto de hegemonia. Sequência: Estudos Jurídicos e Políticos. Santa Catarina:

Universidade Federal de Santa Catarina. vol. 12, p. 85-95, n. 23, 1991.

CPDOC - FGV (Centro de Pesquisa e Documentação de História Contemporânea do Brasil). Álvaro Vieira Pinto. Disponível em:

<http://cpdoc.fgv.br/producao/dossies/AEraVargas2/biografias/alvaro_vieira_pinto.> Acesso em: 23 jan. 2013.

DIAS, Silvano Severino; Araújo, José Carlos Souza. A concepção de educação nacionalpopular em Vieira Pinto. Cadernos de História da Educação, v. 1, n. 1, p. 103-108, jan./dez., 2002.

FAUSTO, Boris. O Período Democrático (1945-1964). In: História do Brasil. São Paulo: Editora da Universidade de São Paulo. 2007. p. 395-462.

FÁVERO, Maria de Lourdes de Albuquerque. A Universidade no Brasil: das origens à Reforma Universitária de 1968. Educar em Revista, Curitiba, vol. --, n. 28, p. 17-36, jul./dez., 2006.

FERNANDES, Florestan. Universidade brasileira: reforma ou revolução?. São Paulo: Alfa e Omega, 1975.

FREITAS, Marcos Cézar de; BICCAS, Maurilane de Souza. A Reforma Universitária de 1968: a resposta à radicalização do movimento estudantil. In: História social da educação no Brasil (1926-1996). São Paulo: Cortez, 2009. p. 265-272.

FREITAS, Marcos Cézar de. Álvaro Vieira Pinto: a personagem histórica e sua trama. São Paulo: Cortez; USF-IFAN, 1998.

Brasil 1954-1964: sugestão de roteiro a partir da "História das Ideias

Educacionais" (Anísio e Vieira Pinto). Revista Brasileira de História. v. 14, n. 27, p. 167-178. Disponível em:

<http://www.anpuh.org/revistabrasileira/view?ID_REVISTA_BRASILEIRA=16 >. Acesso em: 31 jul. 2013. 
. Economia e educação: a contribuição de Álvaro Vieira Pinto para o estudo histórico da tecnologia. Revista Brasileira de Educação. Campinas, v. 11. n. 31. p. 8095, jan./abr., 2006.

I SEMINÁRIO NACIONAL DE REFORMA UNIVERSITÁRIA. Revista Brasileira de Estudos Pedagógicos. Rio de Janeiro: Instituto Nacional de Estudos Pedagógicos. vol. XXXVI, n. 83, p. 235-242, jul./set., 1961.

LIBÂNEO, José Carlos; OLIVEIRA, João Ferreira de; TOSCHI, Mirza Seabra.

Educação Escolar: políticas, estrutura e organização. São Paulo: Cortez, 2009.

MOROSINI, Marilia Costa. O ensino superior no Brasil. In: STEPHANOU, Maria; BASTOS, Maria Helena Câmara (Orgs.). Histórias e memórias da educação no Brasil: século XX. Petrópolis, RJ: Vozes, 2005. p. 296-323.

PARTICIPAÇÃO DISCENTE NA DIREÇÃO DA UNIVERSIDADE. Revista

Brasileira de Estudos Pedagógicos. Rio de Janeiro: Instituto Nacional de Estudos Pedagógicos. vol. XXXVIII, n. 87, p. 203-209, jul. set., 1962.

ROMANELLI, Otaíza de Oliveira. História da educação no Brasil (1930-1973). Petrópolis: Vozes, 1978.

SAVIANI, Dermeval. Prefácio (A questão da Universidade). In: VIEIRA PINTO, Álvaro. A questão da Universidade. São Paulo: Cortez; Autores Associados, 1986. p. 7-9. Introdução. In: VIEIRA PINTO, Álvaro. Sete lições sobre educação de adultos. São Paulo: Cortez, 1997. p. 09-27.

Álvaro Borges Vieira Pinto. In: FÁVERO, Maria de Lourdes de Albuquerque; BRITTO, Jader de Medeiros. (Orgs.). Dicionário de educadores no Brasil. Rio de Janeiro: Editora UFRJ; MEC-Inep-Comped, 2002. p. 51-56.

TEIXEIRA, Anísio. Educação não é privilégio. Rio de Janeiro: Editora UFRJ, 1994.

VEIGA, Laura da. Reforma Universitária na década de 60: origens e implicações políticoinstitucionais. Revista Ciência e Cultura, São Paulo, vol. 37, n. 7, p. 86-97, 1985.

VIEIRA PINTO, Álvaro. Consciência e realidade nacional. Volume 1. Rio de Janeiro: Ministério da Educação e Cultura; Instituto Superior de Estudos Brasileiros, 1960a.

Consciência e realidade nacional. Volume 2. Rio de Janeiro: Ministério da Educação e Cultura; Instituto Superior de Estudos Brasileiros, $1960 \mathrm{~b}$.

A questão da universidade. São Paulo: Cortez; Autores Associados, 1986.

. Sete lições sobre educação de adultos. São Paulo: Cortez, 1997.

\section{Notas}

\begin{tabular}{l}
${ }^{1}$ Doutoranda em Educação pelo Programa de Pós-Graduação em Educação da Universidade Estadual de \\
Maringá (UEM). Participa do Grupo de Pesquisas e Estudos História da Educação, Intelectuais e \\
Instituições Escolares (UEM), cadastrado no Diretório dos Grupos de Pesquisa - CNPq. E-mail: \\
cristianesilme@yahoo.com.br \\
${ }^{2}$ Doutora em Educação pela Universidade Estadual de Campinas (UNICAMP). Coordenadora do Grupo de \\
Pesquisas e Estudos História da Educação, Intelectuais e Instituições Escolares (UEM). Participa do Grupo \\
\hline
\end{tabular}

Revista HISTEDBR On-line, Campinas, $n^{o}$ 53, p. 263-279, out2013 - ISSN: 1676-2584 
de Estudos História, Sociedade e Educação no Brasil (HISTEDBR). Professora do Programa de PósGraduação em Educação da Universidade Estadual de Maringá (UEM). Pesquisadora nível 1D do CNPq. Email: mcgmachado@uem.br

${ }^{3}$ O livro Consciência e Realidade Nacional é composto por dois volumes. Vieira Pinto o concluiu em 1959. Os volumes foram publicados em 1960. Freitas (1998) assinala que "Consciência e Realidade Nacional, como unidade discursiva, representa com maior amplitude as tendências políticas do ISEB no período de 1960-1964, entre os quais Álvaro Vieira era apenas uma, porém, aquela que maior atenção dedicava ao terceiro mundo." (FREITAS, 1998, p. 88).

${ }^{4}$ O livro Sete Lições sobre Educação de Adultos reúne textos do autor redigidos como roteiros de aulasconferências proferidas no Chile em 1966. (SAVIANI, 1997).

Recebido em outubro-13

Aprovado em novembro-13 